\title{
1986 in Review
}

\author{
Gordon E. Pike \\ MRS Immediate Past President
}

In announcing the 1977 Fall Meeting, MRS President Rustum Roy produced the first review of the Society's operations: "It is disorganized, has amorphous leadership, 'with no staff, no overhead, no fancy brochures." In the short temporal span since that announcement, the Materials Research Society has grown by a factor of 20 and, for better or for worse, those characteristics have all changed. Unchanged, though, is the dedication to the original purposes of the Materials Research Society and the enthusiasm of members working toward the realization of those purposes.

To enumerate all the people and projects that were active during 1986 would be a hopeless task for me-I would inadvertently miss many. Instead, I will present only the highlights of this past year.

The principal driving force for establishing the Materials Research Society was the need for an interdisciplinary forum for the discussion of specific materials topics. That need was fulfilled in 1986 by our two technical meetings. The Spring Meeting in Palo Alto, CA was organized by Wei-Kan Chu, Rod Quinn, and Malcolm Thompson. It was enhanced by the first MRS outdoor, poolside poster session, which was at least as spirited as the chili cookoff preceeding it. The nine topical symposia at this meeting are a substantial increase in number from the four symposia offered at the initial MRS Spring Meeting in 1984. The Fall Meeting just completed featured 22 topical symposia, and was organized by Bob Chang, Carol Jantzen, and Jim Roberto. Each meeting was deliberately planned to be interdisciplinary - and also to cover a wide variety of materials to provide a cross-fertilization among seemingly disparate research fields. The Meeting Chairs and Symposium Organizers for both meetings devoted many late hours of work to create the type of meeting most useful to materials researchers. The success of their efforts can be measured in many ways, but the most obvious is the record-breaking attendence at each meeting.

Dissemination of information useful to the materials research community - a stated objective of the Materials Research Society - was accomplished in 1986 through three publications media - the Symposia Proceedings series, Journal of Materials Research, and the MRS BULLETIN. Under the direction of the Publications Committee, chaired by David Campbell - and particularly its Subcommittee on Books, chaired by Peter

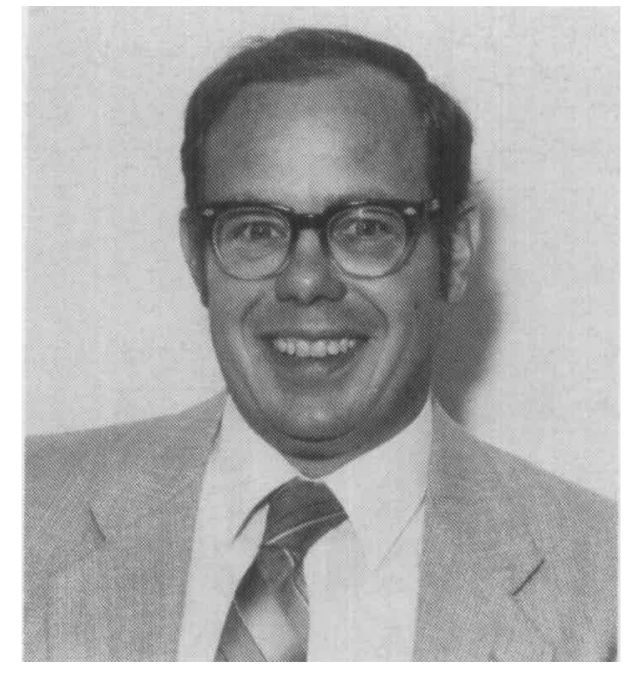

Pronko - the proceedings of 23 recent MRS symposia were published. In addition, a new Conference Proceedings series, for non-MRS symposia related to materials research, was inaugurated with the publication of Tungsten and Other Refractory Metals for VLSI Applications. Agreements for several more books in this new series have already been secured.

Following 18 months of intensive planning, Journal of Materials Research became a reality with the appearance of its first issue in April 1986. Although this issue was delayed a few months, the last issue of Volume 1 is now on schedule due to the diligent efforts of Editor-in-Chief Charles Duke and his Board of Principal Editors. $J M R$, the official technical journal of the Materials Research Society, was established to offer its constituency the same broadly based interdisciplinary research results found at its meetings. The quality and breadth of topical coverage in JMR has been monitored and stimulated this year by the Publications Subcommittee on Journals, chaired by Ross Lemons. This group has also aided the rapid acceptance of the Journal by hundreds of technical libraries.

The third medium showing significant progress in 1986 is the one in which this article appears. The MRS BULLETIN under the guidance of its Editorial Board Chairman, Elton Kaufmann, has made tremendous strides in its transformation from simply a Society newsletter to a magazine with broad news coverage plus technical articles (at a generally understood level) about forefront developments in materials. In terms of publications alone, 1986 has been an exciting year for MRS.

MRS educational activities have also increased significanily this past year. This is most striking in the Short Course Program, managed for the first time by Vivienne Harwood Mattox under the direction of Education Committee Cochair Ralph Dawson. Programs of 16 and 23 short courses were offered in conjunction with the Spring and Fall Meetings, respectively. In addition, several On-Site Short Courses were given at industrial locations, and a two-course program was cosponsored with the New Mexico Section of MRS. Considerable effort was devoted to the development of new courses emphasizing topics covered in the technical symposia.

The 1986 Fall Meeting was the scene of a new educational venture for MRS - the videotaping of interviews with several founders of modern materials research in support of our History of Materials Research project. This two-year project is being organized by Rustum Roy.

In addition to various internal projects, MRS has, during the past year, interacted with other groups concerned with materials. MRS cosponsored ten technical meetings or symposia, and provided publicity assistance for five more. In April at the Palo Alto, CA meeting, MRS provided a venue for an ad hoc group of 25 scientists from many groups. Representing a wide range of materials research interests, they discussed the needs and opportunities for creating a spokesgroup capable of effecting a two-way information flow on materials issues between researchers and government officials. While no formal action resulted from this meeting, its purpose of stimulating discussion among many groups did succeed. Finally, MRS responded to a request for input to the national Materials Science and Engineering Study by soliciting brief papers from its membership. These papers were published in November in Communications on the MSE Study, and a subset were selected for presentation at the Forum on the MSE Study at the 1986 Fall Meeting. The Forum, featuring presentations from MSE Study panel representatives, was designed to encourage discussion directly between the Study members and MRS members.

Only a small fraction of all these activities would be possible without consider-

Continued 
able support from MRS headquarters in Pittsburgh, PA. A specific goal this past year was to extend headquarters' assistance to the Meeting Chairs and Symposium Organizers. To accomplish this goal, plus accomodate a $35 \%$ membership increase, the headquarters staff and space were substantially expanded. Three new positions were filled, and two floors of office space were consolidated into a larger, one-floor operation. In the midst of other ongoing activities, the outmoded com- puter system was replaced with a new system specifically designed for association operations. Although pinched for training time, headquarters staff were able to complete the entire Fall Meeting preregistration on the new system. It is anticipated that this system will considerably increase the efficiency and productivity of the headquarters office, particularly in data and word processing.

Throughout this past year it has been a distinct privilege for me to work with so many able, innovative, dedicated individuals. This is particularly true of the officers - Elton Kaufmann, Kathy Taylor, John Baglin, Rod Ewing, and Clif Draper - all of whom contributed to many aspects of the Society's operation. With people like these to assist the new president, Kathy Taylor, we can look forward to another productive year full of new activities.

MRS

\section{Subscribe to}

\section{MATERIALS LETTERS}

\section{At Special MRS Member Rates}

As a member of the Materials Research Society, you can subscribe to Materials Letters at a special subscription rate. Only members of MRS may receive personal subscriptions to this valuable journal.*

Volume $V$ of Materials Letters will be completed during 1987. To receive the first issue of Volume $V$ as soon as it is published this year, subscribe now by completing the form below. For your convenience, you may also subscribe to Volume Vl to ensure continuation of your subscription after Volume $V$ without pause in service.

*Institutional subscriptions for libraries must be obtained through the publisher. Elsevier Science Publishers B.V., Journal Department, P.O. Box 211. 1000 AE Amsterdam. The Netherlands.

\section{MATERIALS LETTERS}

l am a member of the Materials Research Society and wish to subscribe to the following volumes of Materials Letters at the special MRS member personal subscription rate.

Check appropriate volume(s):

Volume V (current volume) @ $\$ 20.00$

$\$$

Volume VI ↔ $\$ 20.00$

$\$$

TOTAL ENCLOSED

$\$$

Name

Organization

Address

City State Zip/Postal Code

Country

Return subscription order with payment to: Materials Letters Subscription, Materials Research Society, 9800 McKnight Road, Suite 327, Pittsburgh, PA 15237; telephone (412) 367.3012 